\title{
Die „Nähe unseres Glücks“. Zur Dialektik der Abwesenheit in Johannes von Müllers Briefen an Graf Louis Batthyány Szent-Iványi
}

\section{Vorüberlegungen - Zur antinomischen Räumlichkeit und Psychologie des Liebesbriefes}

Ohne jeden Zweifel bedarf der Brief, um überhaupt verfasst zu werden, der räumlichen Distanz zwischen Schreiber und Adressat; ${ }^{1}$ dabei kann diese Distanz lediglich einige Meter betragen, wie in Samuel Richardsons Clariss $a,{ }^{2}$ oder Tausende von Kilometern, wie in Françoise de Grafignys Lettres d'une Péruvienne ${ }^{3}$ - erst die E-Mail hat die quantitative Dimension epistolarer Räumlichkeit (und damit der Zeit) irrelevant werden lassen, ohne deren qualitative Bedeutung, nämlich die Tatsache, dass es überhaupt der räumlichen Distanz bedarf, aufzuheben. ${ }^{4}$ Unabhängig von dieser zugleich qualitativ notwendigen, in ihrer Quantität jedoch kontingenten räumlichen Distanz versucht der Brief, und hierbei insbesondere der Liebesbrief, diese Distanz zu überwinden, d.h. zumindest die intellektuellen und - im Falle des Liebesbriefes ${ }^{5}$ - auch emotiven Elemente der direkten Interaktion kommunikativ zu substituieren. ${ }^{6}$ Es ist jener dem Brief wesentlich zukommende Substitutionsprozess, der mit der unglücklichen Metapher vom Brief als ,halbem Gespräch` zu fassen gesucht wurde. ${ }^{7}$ Unglücklich ist diese Metapher, weil sie die durch die Schriftlichkeit des Briefes erzwungene spezifische Bewusstseins- und Reflexionsleistung, die der Briefschreiber gegenüber einem Gespräch und des-

1 Vgl. hierzu u. a. Miller 1968, 147-151.

2 Richardson 1967 (1748), Vol. 1, 103-110.

3 Grafigny 2020 (1747).

4 Vgl. hierzu in Ansätzen König u. Ziegenhain 2020.

5 Vgl. hierzu insbesondere Stauf et al. 2008.

6 Diesen antinomischen Charakter des Liebesbriefes betont schon Rousseau 1964 (1761), 15-17.

7 Zur Geschichte und Bedeutung dieser Metapher vgl. Vellusig 2000.

Gideon Stiening, Westfälische Wilhelms-Universität Münster

Ә Open Access. (c) 2021 Gideon Stiening, publiziert von De Gruyter (cc) BY-NC-ND Dieses Werk ist lizenziert unter der Creative Commons Attribution-Non-Commercial-NoDerivatives 4.0 International Lizenz.

https://doi.org/10.1515/9783110712568-011 
sen Reflexionsformen zu erbringen hat, unberücksichtigt lässt, und damit das Proprium des Briefes in ein Defizit (halbes Gespräch) verlegt.

Denn die erforderliche Schriftlichkeit des Briefes generiert die Urteilsform des Gedankens - noch die spezifisch briefrhetorischen Instrumente wie Aposiopese, Onomatopoetika oder Ellipsen können nur erfolgreich als Darstellung emotiver Beteiligung eingesetzt werden, wenn sie in einem diskursivem Umfeld stehen ${ }^{8}$ - und damit argumentationslogische und begründende Sprachformen, die im face-toface-Gespräch nicht stets notwendig sind. Die Schriftlichkeit des Briefes ist folglich nicht allein Defizitkompensation, sondern auch und vor allem Rationalitätsgewinn, noch im emotivsten Liebes-Brief. ${ }^{9}$

Diese durch die Urteilsform unhintergehbare Rationalität des Briefes kann aber - bei aller räumlichen Distanz - die psychische und mentale ,Nähe‘ zwischen Schreiber und Empfänger maßgeblich verstärken, weil in diesem Medium - anders als im Gespräch - Sachverhalte ,zur Sprache kommen' können, die beispielsweise durch situationsethische Vorgaben eines Gespräches oder durch die mangelnde Distanz zur Logik der eigenen mündlichen Rede - zumal im Anblick eines geliebten, womöglich gar begehrten Menschen - verhindert werden. ${ }^{10}$ Die räumliche Distanz kann also, weil sie zur epistolaren Mitteilung drängt, zu einer größeren psychischen oder intellektuellen Nähe führen, gerade weil im Brief Sachverhalte formuliert werden können, die im Gespräch unmöglich sind. ${ }^{11}$

Das hat vor allem damit zu tun, dass der Brief - stärker noch als das Gespräch, weil nämlich durch Einwände nicht unterbrochen - ein Instrument der Selbstdarstellung, ${ }^{12}$ ja der ungehemmten egomanen Selbstauslegung sein kann, wie bei

8 Vgl. hierzu Schöne 1967, 193-229; jetzt auch in: Ders. 2015, 73-122.

9 Insofern gehört es nicht allein zu den nicht unerheblichen Geschmacklosigkeiten einer bestimmten Literaturwissenschaft (vgl. hierzu Koschorke 1999), die Tinte eines Briefes mit den durch sie angeblich ersetzten Körpersäften zu korrelieren, sondern dieser ,Vergleich“ ist schlicht falsch, weil der o.g. Rationalitätsgewinn des Briefes in dieser ,Ersetzungsbeschreibung“ vollkommen unerkannt bleibt. Vgl. hierzu schon Stiening 2001.

10 Vgl. hierzu die kaum je übertroffene Präzision zu diesem Sachverhalt bei van der Heijden 1995, 165: „Der Brief als Mittel, um sich aus einer peinlichen Situation oder einem Konflikt zu retten. Nicht selten hatte er eine Liebesbeziehung auf dem Postwege abgebrochen, und noch häufiger hatte er jemandem auf diese Weise die Freundschaft oder Zusammenarbeit aufgekündigt. Liebeserklärungen, Geständnisse, Vorwürfe, Komplimente, Beleidigungen, Enthüllungen - alles lieber brieflich als Auge in Auge. Gut, er wählte dann zwar die persönlichste aller schriftlichen Ausdrucksformen, aber trotzdem: schriftlich. Das heißt durchdacht, ausgereift, indirekt, unsichtbar, versteckt, schleichend, platonisch. Bei seinen Abrechnungen bediente er sich der Feder, und der schleichende Umweg für das in den Rücken gestoßene Messer wurde bestenfalls legitimiert durch die daraus resultierende Eloquenz.“

11 Vgl. Stiening 2005.

12 Vgl. hierzu u. a. Ludolph 1997, 28-54. 
Rousseau oder Hamann. ${ }^{13}$ Der Brief kann also auch eine andere Distanz durch Nähe ersetzen: die zu sich selbst. Denn wie schon bei Pamela oder bei Werther und Hyperion, deren Autoren ganz bewusst nur eine Seite von Briefwechseln, nämlich die ihrer Protagonisten, präsentieren, geht es vor allem um die möglichst umfassende Darstellung einer Individualität, deren Konturen durch ihre eigenen Urteile allererst gezeichnet werden. Hier ist der Brief erst recht kein Gespräch mehr, auch kein halbes, sondern ein in der Selbstaussprache realisiertes Selbstverhältnis, ${ }^{14}$ das des Adressaten nur mehr als Anlass bedarf, und so ist von Dialog, also Interpersonalität oder gar Geselligkeit, in dieser Funktion des Briefes kaum mehr etwas zu entdecken. Für Werther, Hyperion oder auch den Historiker Johannes von Müller, der uns in der Folge beschäftigen wird, ${ }^{15}$ haben Briefe vor allem selbstreflexiven und -explikativen Wert und dienen damit zur Erkenntnis und Ausstellung der eigenen Individualität; das kann ein schmerzvoller Prozess sein, wie bei Hyperion, oder eben lustvoll, wie bei von Müller, Hamann oder Goethe, die sich in ihren Briefen vor allem mit ihrem lebenslang wichtigsten Gegenstand beschäftigten: sich selbst. ${ }^{16}$

Gleichwohl bleiben auch diese Selbstausstellungen an einen oder mehrere Briefpartner gebunden (anders als das Tagebuch) und bieten daher - wie jede Interpersonalität - neben den Möglichkeiten zur authentischen Selbstaussprache, der kritischen Erwiderung, des offenen Streits oder der klugen Überredung auch die Möglichkeit des Betruges. Dabei offerieren die Bedingungen epistolarer Kommunikation unterschiedliche Formen der Täuschung - von der Fehlinformation (den heute so berühmten fake news) über habituelle oder positionelle Verstellung bis hin zur Lüge über die eigene Person des Schreibers bzw. Empfängers. Die Fülle an Varianten des epistolaren Betrugs ist enorm. ${ }^{17}$ Besonders drastisch fällt der Betrug in psychischer, ethischer, bisweilen auch rechtlicher Hinsicht unter den Bedingungen einer epistolaren Liebesgemeinschaft aus, weil in diesem Zusammenhang starke, auch entblößende intime Bekenntnisse eines emotiv an seinem Schreiben stark beteiligten Individuums zu einem Mittel für äußere, zumeist schädliche Zwecke missbraucht werden. Hier wird die vermeintliche Nähe zu jener zumindest nach der Entlarvung - maximalen Distanz auch in der subjektiven Hinsicht des Betrogenen, die sie für den Betrüger je schon war. Gottfried Keller hat

13 Vgl. hierzu Beetz et al. 2016 sowie demnächst Stiening (im Druck).

$14 \mathrm{Zu}$ diesem Begriff vgl. Henrich 1993.

$15 \mathrm{Zu}$ von Müller vgl. u. a. Henking 1909-1928 sowie Schib 1967.

16 Vgl. hierzu u. a. Hamann 2018 (1785-1787), Bd. 2, 23, wo der Autor „vom höchste[n] Ideal und Idol allgemeiner Autorschaft, Mich Selbst“, spricht.

17 Vgl. hierzu jetzt Bredthauer 2020. 
diesen Sachverhalt in seiner satirischen Erzählung Die missbrauchten Liebesbriefe in bedrückender Weise realisiert. ${ }^{18}$

Johannes von Müller hat einen solchen epistolar-gestützten Betrug tatsächlich über sich ergehen lassen müssen, was im Folgenden näher betrachtet werden soll. Dabei wird sich zum einen zeigen, dass die räumliche Distanz des betrügerischen Schreibers jener Briefe, die Müller in Liebe tatsächlich entflammen ließen, kaum geringer hätte sein können, während die psychisch emotive Nähe eine Illusion war, weil es den erfundenen Schreiber jener Briefe gar nicht gab, und so größer nicht hätte sein können.

Nähe und Distanz sind Bedingungen der Möglichkeit epistolarer Kommunikation - auch und gerade in Liebesdingen; sie sind, wie die Liebe, ${ }^{19}$ kulturell konditioniert und ändern daher unter den sich verändernden gesellschaftlichen Bedingungen ihre Kontur. Besonders anschaulich wird diese Dependenz - wie schon die Briefwechsel zwischen Abaelard und Heloisa sowie Julie und SaintPreux zeigten - in negativ sanktionierten, mithin verbotenen Liebesbeziehungen. Johannes von Müllers rechtlich wie moralisch um 1800 verbotenen homosexuellen Neigungen dokumentieren die kulturelle Bedingtheit von Nähe und Distanz im und durch den Brief in besonders schmerzlicher Weise.

\section{Historischer Kontext}

Dem im Folgenden zu betrachtenden Briefwechsel, ${ }^{20}$ der zwischen Juni 1802 und März 1803 geschrieben und ausgetauscht wurde, wobei nur die eine Seite desselben überliefert wurde, nämlich die von Müllers, liegt ein realhistorisches Geschehen zugrunde, das es zu kennen und daher kurz zu referieren gilt. ${ }^{21}$ Der europaweit bekannte, in einem dichten Netzwerk von Briefbekanntschaften agierende Historiker und Verwaltungspolitiker Johannes von Müller (1752-1809), 22 Freund und geschätzter Kollege immerhin Herders, Goethes, Gentzens oder Gleims, nimmt Mitte der 1790er Jahre Friedrich von Hartenberg, den knapp 15-jährigen Sprössling eines verarmten süddeutschen Beamtenadelsgeschlechts unter seine Fittiche. ${ }^{23}$

18 Keller 1993 (1874).

19 Vgl. hierzu u. a. Benz 2018.

20 Müller 2014.

21 Zum Folgenden vgl. u. a. Henking 1909-1928, Bd. 2, 545-586; Derks 1990, 295-368 sowie Weibel 2014.

$22 \mathrm{Zu}$ von Müller als Historiker vgl. u. a. Jamme u. Pöggeler 1986 sowie Süßmann 2004.

$23 \mathrm{Zu}$ von Hartenberg vgl. Weibel 2014, 66-106. 
Von Müller ist nach einer seit den frühen 1770er Jahren währenden abenteuerlichen Odyssee durch die Kulturzentralen der europäischen Aufklärung seit 1792 auf Einladung Franz' II. am Wiener Hof tätig, und zwar als Diplomat an der Geheimen Hof- und Staatskanzlei, mithin im machtpolitischen Zentrum der österreichischen Monarchie während des Revolutionsjahrzehnts, sowie ab 1800 als Kustos an der Hofbibliothek, einer politisch unbedeutenden Versorgungsstelle. Beide Stellungen ermöglichen ihm ein weitgehend sorgenfreies Leben mit immerhin 115 Urlaubstagen im Jahr, wie er mehrfach im Briefwechsel betont. ${ }^{24}$

Von Hartenberg hingegen, ,ein bildschöner, sinnlicher, beredter und skrupelloser junger Mann“, ${ }^{25}$ wie es im Nachwort zur jüngsten Edition des Briefwechsels heißt, steht am Beginn einer verwaltungspolitischen Karriere an einem der europäischen Höfe des späten, von der Französischen Revolution aufgewühlten achtzehnten Jahrhunderts. 1796 nimmt er, aufgewachsen im Fürstentum Fürstenberg, in Villingen und Wien, wohin seine Mutter als Witwe nach dem Tode des Vaters flüchtet, Kontakt zu von Müller auf, um sich von ihm protegieren zu lassen: „Im Spätjahr 1795 hinterließen Josepha von Hartenberg und der vierzehnjährige Fritz erstmals beim k.k. Hofrat Johannes von Müller ihre Visitenkarte.“26 Die Wahl von Müllers durch Mutter und Sohn Hartenberg zwecks Nachfrage nach einer im absolutistischen Wien nicht unüblichen Protektion kam wohl nicht von ungefähr: Während der schöne, hochaufgeschossene Teenager offenbar eine starke homoerotische Ausstrahlung hat, ist von Müller im Rahmen der subpublizistischen Öffentlichkeit, also in dem, was man innerhalb des aristokratischen Gesellschaftmodells ,den Ruf' nennt (anschaulich in Szene gesetzt in den Liaisons dangereuses), als Homosexueller bekannt, so dass die von Hartenbergs offenbar mit dem erotischen Kapital des Sohnes hausieren gingen. Ohne Zweifel liegen hier spezifische Formen von Prostitution vor, die allerdings einen eigenen Status innerhalb des aristokratischen Patronagesystems innehatte. ${ }^{27}$

Nach einigem Hin und Her lässt sich von Müller auf diese Protektion ein, allerdings nicht, indem er die Vormundschaft über Fritz von Hartenberg übernimmt, was die Mutter offenbar erhofft hatte, sondern indem er ihm Stipendien für Reisen und Universitätsausbildungen zu verschaffen zusichert, die den jungen Adeligen auf eine Verwaltungslaufbahn vorbereiten sollen und die Fritz von Hartenberg zwischen 1797 und 1799 in Prag und Wien zu vernutzen weiß - ohne allerdings tatsächlich Studien zu betreiben. 1799 wird er wegen angeblicher Epilepsieanfälle aus dem Wiener Theresianum entlassen. Schon zu diesem Zeitpunkt ist eigentlich

24 Weibel 2014, 29.

25 Weibel 2014, 66.

26 Weibel 2014, 73.

27 Vgl. hierzu Weibel 2014, 77-78. 
klar, dass der zu Faulheit und Eitelkeit, zudem zu aristokratischem Dünkel neigende Jüngling wenig für ein Studium oder gar eine Verwaltungskarriere taugt. Als launische Diva, die sich mehr mit ihrem Äußeren als mit dem Wissenserwerb beschäftigt, verkehrt von Hartenberg sowohl in Prag als auch in Wien vorzugsweise in adeligen Kreisen mit homoerotischen Realisationsmöglichkeiten sowie in einem Strichermilieu, die beide dem schönen und durchaus gebildeten jungen Mann zu Füßen liegen. Seinem Standesverständnis gemäß, aber weit über die Möglichkeiten hinaus, die ihm Müller mit den Stipendien verschaffte, übersteigen seine Ausgaben schnell seine Einnahmen, so dass er Schulden machen muss. Nach seiner Rückkehr nach Wien scheint er diesen Lebenswandel vor allem durch eine Existenz als Mätresse vermögender Militärs und Verwaltungsbeamter der Wiener Gesellschaft finanziert zu haben. Doch reichten diese Aktivitäten offenbar nicht aus, seinen enormen Finanzaufwand zu begleichen.

Dies ist eine grobe Skizze der Vorgänge; wir wissen von all dem wenig. Schwer ist es auch, die tatsächlich vorhandenen Dokumente einzuschätzen, weil noch viel zu wenig an einer Sozial- und Kulturgeschichte der Homosexualität um 1800 geforscht und über sie geschrieben wurde. ${ }^{28}$ Sicher dagegen ist, dass sowohl Johannes von Müller als auch Friedrich von Hartenberg ihre sexuelle Orientierung übrigens zeitweilig wohl auch miteinander ${ }^{29}$ - durchaus realisieren konnten, auch wenn vor allem von Müller mehrmals Karrierestufen nicht erklimmen konnte, ${ }^{30}$ weil er offenbar allzu offen seine ,attische Liebe‘ ausstellte. Die folgende Betrachtung der Briefe des unsterblich verliebten von Müller sind - so scheint es - im Hinblick auf das Thema ,Nähe und Distanz' einerseits in ihrer Grundlegung in einer homoerotischen ,Beziehung ' von besonderem Interesse; andererseits wird diese Perspektive durch den Betrug realisiert, durch den diese Briefe allererst veranlasst werden.

\section{Die Hartenberg-Intrige}

Entscheidend ist nämlich, dass Friedrich von Hartenberg, der nach seinem Austritt aus dem Theresianum wieder in einem Hinterzimmer bei seiner verarmten Mutter wohnen musste, seinen unbedingten Willen zu und seine Lust an einer Existenz innerhalb der aristokratischen Hochkultur der Wiener Innenstadt nur durch neue Geld-Quellen erreichen konnte. Im Sommer 1802 hat er sich endgültig

28 Vgl. hierzu u. a. Derks 1990 sowie neuerdings Domeier, Mühling (Hg.) 2020.

29 Vgl. hierzu Weibel 2014, 77.

30 Weibel 2014, 51-53. 
davon überzeugt, mit einem handfesten Betrug seinem Gönner mehr als die paar Taler Rente zu entlocken, die er neben einigen anderen kleineren Zuschüssen von anderer Seite erhielt. Dieser Betrug bestand nun darin, die Sehnsüchte des alternden und politisch wie kulturell unter prekären Bedingungen lebenden von Müllers nach einer echten, intellektuell, emotional wie sexuell tatsächlich befriedigenden Liebebeziehung auszunutzen. Von dieser Sehnsucht hatte von Hardenberg schnell erfahren können, war sein Mäzen doch häufig bereit, den jungen Protegé auch intellektuell und kulturell zu bilden. Müller war zwar - auch in seinem Alter sexuell aktiv, ${ }^{31}$ er sehnte sich aber nach mehr und anderem als den schnellen Befriedigungen der Lust mit jungen Strichern oder solchen Protegés wie von Hartenberg. Von Müller suchte nach einer homosexuellen Seelenverwandtschaft, die ihm mit einem sehr viel jüngeren, zudem abhängigen Mann nicht möglich schien; schon als junger, aufstrebender Intellektueller hatte von Müller mit Karl Viktor von Bonstetten eine solch idealisierte Liebesbeziehung auszuleben versucht, ${ }^{32}$ bis der ein paar Jahre ältere Geliebte zum Zwecke der Beförderung seiner akademischen und institutionellen Laufbahn eine Ehe schloss - ohne den Freund davon zu informieren. Dem einige Jahre er- und gelebten Liebesideal scheint von Müller sein Leben lang hinterhergelaufen zu sein, auch wenn er seinen derben Neigungen zu übergriffiger Sexualität - vor allem im trunkenen Zustand - durchaus zeitlebens Raum bot. ${ }^{33}$

Von Hartenberg beginnt also im Juni 1802 unter dem Namen Graf Louis Batthyány Szent-Iványi einen Briefwechsel mit von Müller, in dem dieser 37-jährige, also in den besten Jahren befindliche ungarische Aristokrat aus einer der reichsten und ältesten Familien des Habsburgerreiches seine tiefe Zuneigung zu dem 14 Jahre älteren Gelehrten gesteht, die ausschließlich aus der Lektüre seiner Schriften erwachsen sei. Diese Zuneigung sei so stark, dass er sich aus der Öffentlichkeit zurückzuziehen gedächte, um mit von Müller ein gemeinsames Leben auf Reisen und an den verschiedenen Residenzen der Familie zu führen. Von Hartenberg scheint den richtigen Ton sowie den ,wunden Punkt' von Müllers präzise getroffen zu haben, reagiert dieser doch überaus positiv, d.h. in einer vollkommen enthemmten Verliebtheit, die sich also ebenfalls ausschließlich aus schriftlichen Zeugnissen, hier Briefen, ergibt; so heißt es schon im zweiten der erhaltenen Briefe: „Aber ich schwöre dir, bislang noch nie ein Herz gefunden zu haben, das mit meinem so sehr in Einklang gewesen wäre, überzeugt, dass wir uns von nun an nie wieder trennen werden.“34

31 Vgl. Weibel 2014, 31-33.

32 Vgl. hierzu Johannes von Müllers Briefe an Carl Viktor von Bonstetten (Müller 1835).

33 Vgl. Weibel 2014, 59-60.

34 Müller 2014, Bd. I, 19. 
Bevor zu einer Betrachtung dieses briefhistorischen Sachverhalts überzugehen ist, mag eine letzte realgeschichtliche Bemerkung hilfreich sein, um die Kontextskizze und deren Stellung zur Interpretation der Briefe im Hinblick auf das Thema ,Nähe und Distanz‘ zu verdeutlichen: Friedrich von Hartenberg schreibt diese Briefe mit dem Ziel, nach der Herstellung eines Liebes- und damit Vertrauensverhältnisses zwischen Batthyány und von Müller, den Grafen in die Lage zu versetzen, Müller zu Zahlungen an ihn, Friedrich von Hartenberg, als gemeinsamen Protegé zu veranlassen, die er ihm - aus reichstem Hause stammend - umgehend zurückerstatten würde. Diese Konstellation ist so durchsichtig, dass man kaum glauben kann, dass Müller tatsächlich auf sie eingeht - zumal niemand anderes als von Hartenberg der Überbringer der Episteln in beide Richtungen ist. Der tatsächliche Schreiber jener Briefe, in deren Verfasser sich von Müller unsterblich verliebt, ist ihm also so nahe wie niemand sonst - es gibt ausführliche vertraute Gespräche zwischen von Hartenberg und von Müller über Batthyány; Müller liest dem ,Boten“ unter Tränen aus den Briefen des Grafen vor, der je schon und stets auf Distanz bleibt und bleiben muss, weil es ihn nicht gibt. Von Hartenberg ist also nicht allein ein brillanter Betrüger, sondern auch ein ebenso brillanter Briefschreiber, in den von Müller sich - weil nur aufgrund der Briefe - eigentlich verliebt - ohne es zu wissen. Nähe und Distanz sind in dieser Konstellation also zugleich nichtig und absolut, wobei die Dynamik dieser eigentümlichen Dialektik aus den betrügerischen Absichten des verschuldeten von Hartenberg generiert und - natürlich auf der Asymmetrie der Kenntnis über die tatsächlichen Bedingungen basiert.

Trotz der für den heutigen Leser erkennbaren Absicht des Brief-Betrügers geht von Müller nach und nach auf die Bitten seines geliebten Batthyány ein und übergibt von Hartenberg nicht nur sein ganzes Vermögen, sondern veruntreut am Ende gar Gelder, die ihm von Dritten anvertraut worden waren. ${ }^{35}$ Nachdem von Hartenberg zwischen Sommer 1802 und Frühjahr 1803 ein Leben in Saus und Braus geführt hat, was von Müller offenbar weder aufgefallen noch zu Ohren gekommen zu sein scheint, wird der Betrug entdeckt: Von Hartenberg muss ins Gefängnis und Müller nicht nur Wien verlassen, weil die nur halböffentlich akzeptierte, nunmehr aber öffentlich gemachte Homosexualität rufzerstörend und so existenzvernichtend ist. Obwohl er als berühmter Historiker zunächst in Berlin, später durch Eingreifen Napoleons im Königreich Württemberg, zu hohen Ämtern gelangt, ${ }^{36}$ bleibt er zudem bis zu seinem Tode 1809 heillos verschuldet. ${ }^{37}$

35 Weibel 2014, 134-136.

36 Vgl. hierzu auch Pape 1989.

37 Vgl. hierzu Weibel 2014, 63 sowie die jämmerlichen Bittbriefe Müllers in Müller 2014, Bd. II, 419-458. 
Zwischen dem Beginn und der Aufdeckung der Intrige des Hochstaplers von Hartenberg liegen nicht nur 10 Monate des geradezu gleißenden Glücks für von Müller; dazwischen liegt die Entstehung von mehr als 100 Liebesbriefen an Batthyány, die für den auf unmittelbare Zusammenkunft stets drängenden von Müller zwar nur Surrogatcharakter hatten; weil von Hartenberg aber zuverlässig jedes anberaumte Treffen zu vereiteln wusste, blieben diese Briefe die einzige ,Ausbeute‘ jener Liebe, und doch - oder vielleicht gerade deswegen - gehören sie zu den schönsten Liebesbriefen, die das achtzehnte und frühe neunzehnte Jahrhundert hervorgebracht haben. Allerdings - und auch hier zeigt sich das müllersche Selbstverhältnis als das zentrale Moment des Briefwechsels - hatte der Verliebte am 30. Oktober 1802 an den eigenen Bruder geschrieben:

Ausgearbeitet, verzeih, habe ich die letzten Monate nichts, ausser weitläufige etwa 100 Briefe über alle möglichen Gegenstände an meinen Freünd; was in denselben Hertzensangelegenheiten ist, soll so geschrieben seÿn, daß jene an Bonstetten nichts dagegen sind. Uebrigens enthalten sie viele grosse Schilderungen, eine grosse Mannigfaltigkeit von Ideen und Aussichten. Jetzt, $u$. wie sie sind, kann man sie niemanden zu lesen geben; aber mit der Zeit soll Michel oder sonst einer unserer Getreüen sie, etwas purificirt, abschreiben, u. so habe ich nichts dagegen, daß sie einst auch weiter kommen. Gewiß ist in keiner anderen meiner Schriften so viele Seele, keine so con amore geschrieben. ${ }^{38}$

Schon während der Affäre also gelingt Müller jene reflektierende Distanz zu seinen leidenschaftlichen Liebesbriefen, die ihn erkennen lässt, dass seine Briefe „eine hübsche Anlage zu einem Werckgen“ haben, wie es der junge Goethe an Behrisch schrieb, ${ }^{39}$ also zu einem Teil seiner Schriften werden könnten, und gibt auch schon konkrete Handlungsanweisungen für die selbstzensurierenden und vertraulichen Abschreibeprozesse. Müller wird also in den Betrug nicht allein durch seine „Hertzensangelegenheiten“ getrieben, die gleichwohl - auch zur Überbietung der enttäuschenden Bonstetten-Affäre - eine Rolle spielen. Müller hat von Anfang an genügend Distanz zu sich, zu seinem neuen Freund und zu ihrer Liebe, um seinen Briefwechsel als Moment seines schriftstellerischen Ruhmes zu begreifen - und das, obwohl die Auslieferung des eigenen Vermögens zeigt, dass Müller tatsächlich hemmungslos verliebt ist. Die Vernichtung der Briefe des fingierten Grafen mag vor allem der Wut und Enttäuschung über deren trügerischen Status geschuldet sein; ${ }^{40}$ sie sichert aber auch die Einzigartigkeit der müllerschen Briefkunst. Vom ,Briefgenie“ von Hartenberg, der immerhin einen der bedeutendsten Briefeschrei-

38 Brief Johannes Müllers an Johann Georg Müller vom 20. Oktober 1802, zitiert nach Müller 2014, Bd. II, 558.

39 Brief an Ernst Wolfgang Behrisch vom 13. November 1767, in: Goethe ${ }^{3} 1988,63$.

$40 \mathrm{Zu}$ den kaum überlieferten Restbeständen vgl. Müller 2014, Bd. II, 409-413. 
ber um 1800 in den Zustand grenzenloser Verliebtheit versetzen konnte, wissen wir heute nichts mehr.

\section{Der Brief als Grund und Erscheinung der Liebe}

Betrachtet man zunächst den eigentümlichen Handlungsstatus der Briefe selber, ${ }^{41}$ dann zeigt sich, dass sie nicht nur die beschriebenen Ereignisse und Aktionen äußerlich schildern oder reflektieren, sondern, weil Grund der Liebe zwischen den beiden Liebenden, zur Liebeshandlung selbst zu rechnen sind. Allerdings ist dieses Motiv der liebenden Empfindung ausschließlich aufgrund der Lektüre von Briefen zumindest der fiktiven Epistolarkultur des späten achtzehnten Jahrhunderts nicht unbekannt. So lässt Jakob Michael Reinhold Lenz den Protagonisten seines Briefromans Der Waldbruder, Herz, in Liebe zur Gräfin Stella allein aufgrund der Lektüre ihrer Briefe entbrennen. Das führt im 1797 erstmals publizierten Roman jedoch zunächst zu Hymnen auf den Stil jener gräflichen Briefe, die die Liebe Herzens evozieren:

Alles das (Genie und Mitleid etc. pp) leuchtet aus ihren Briefen, die ich gelesen haben, die ich bei mir habe und auf meinem bloßen Herzen trage. Sieh, es lebt und atmet darinnen eine solche Jugend, so viel Scherz und Liebe und Freude, und ist doch so tiefer Ernst die Grundlage von alle dem, so göttlicher Ernst - der eine ganze Welt beglücken möchte. ${ }^{42}$

Ähnliches würde nur fünf Jahre nach dieser Publikation auch von Müller schreiben; ${ }^{43}$ er scheint aber den folgenden Kommentar zu dem bekannten Phänomen der Liebe zu einer Person durch die Kenntnis ihrer Briefe nicht gekannt oder berücksichtigt zu haben:

Ha ha ha, ich lache mich tot, lieber Rothe. Wissen Sie auch wohl, daß Herz in eine Unrechte verliebt ist. Ich kann nicht schreiben, ich zerspringe für Lachen. Die ganze Liebe des Herz, die Sie mir so romantisch beschrieben haben, ist ein rasendes Qui pro quo. Er hat die Briefe einer gewissen Gräfin Stella in seine Hände bekommen, die ihm das Gehirn so verrückt haben, daß er nun ging und sie überall aufsuchte, da er hörte, daß sie in ${ }^{\star \star}$ angekommen sei, um an den Winterlustbarkeiten teilzunehmen. Ich weiß nicht, welcher Schelm ihm den Streich gespielt haben muß, ihm die Frau von Weylach für die Gräfin auszugeben, genug, er hat keinen Ball

41 Zur Unterscheidung zwischen rein darstellenden und handlungskonstitutiven Briefen im Briefroman vgl. Altman 1982, 185-215 sowie Moravetz 1990, 31-33.

42 Lenz 1992 (1797), 385.

43 Vgl. u. a. Müller 2014, Bd. I, 30. 
versäumt, auf dem Frau von Weylach war, und ist überall wie ein Gespenst mit großen stieren Augen hinter ihr hergeschlichen, so daß die arme Frau oft darüber verlegen wurde. ${ }^{44}$

Diese Passagen können nicht nur dokumentieren, dass es das Motiv des SichVerliebens in Personen aufgrund ihrer Briefe schon in der Literatur des späten achtzehnten Jahrhunderts gab und dass durch die spätestens seit Mitte des Jahrhunderts zu verzeichnenden, von Richardson, Rousseau oder La Roche auch intendierten Übergänge von der Fiktion in die Realität der Epistolarkultur und zurück eine solche Identität von Brief und Liebesgefühl nicht unbekannt war, ${ }^{45}$ so dass Müllers lichterlohes Entflammen für Batthyány nur aufgrund von dessen Briefen für diese späte Phase der Hochkultur des Briefes im achtzehnten Jahrhundert nicht völlig ungewöhnlich ist. Im Kontext spezifischer Entwicklungen der Briefkultur des späten achtzehnten Jahrhunderts ist ein solcher Vorgang also durchaus nicht vollkommen ungewöhnlich. ${ }^{46}$ Gleichwohl wird dieses Phänomen auch - und es ist Lenz, der diesen Sachverhalt unnachgiebig deutlich macht - mit einem Sarkasmus überzogen, der bar jeden Mitleids ist und sein will. Müller selbst ist von solchem Spott vollkommen frei; er ist Hals über Kopf verliebt - in sein Verliebtsein und damit die Möglichkeit, Briefe zu schreiben.

Von Hartenberg konnte also in seinem riskanten Spiel durchaus darauf setzen, dass der Virtuose des Briefstils, Johannes von Müller, gut geschriebenen Liebesbriefen seine Aufmerksamkeit zuwenden, ja die Zuneigung zum Absender erwidern würde. Gleichwohl musste dem immerhin gerade 20-jährigen Hochstapler klar sein, welcher Anstrengungen es bedurfte, Müller hinters Licht zu führen, musste dieser, der nach vorsichtigen Schätzungen zeitlebens um die 20.000 Briefe geschrieben und erhalten hat, ${ }^{47}$ doch als ein echter Meister der Epistolarkultur gelten. Immerhin waren kurz vor Beginn der Affäre Briefe Müllers - allerdings unautorisiert - erschienen, die dieser mit Viktor von Bonstetten in den 1770er und 1780er Jahren, also während ihrer sturm- und drängenden Liaison, ausgetauscht hatte. Von Hartenberg hatte also nicht nur Vorbilder für seine Briefe, er hatte auch eine hohe Messlatte, die es zu überwinden galt.

44 Lenz 1992 (1797), 383.

45 Vgl. hierzu u. a. Picard 1971 oder auch Voss 1993.

46 Müller kannte das Motiv auch aus seiner eigenen Brieferfahrung, so schrieb ihm Gleim im Herbst 1780: „,S]chreiben Sie mir keine Stelle mehr ab aus den Bonst. Briefen; ich könnte mich noch mehr verlieben in Bonst. Und dann nicht nach Berlin sondern nach Bern abfahren." Müller 1835, Bd. III, 325.

47 Weibel 2014, 37-39. 


\section{Müllers Liebesbriefe - Konturen einer Interpretation}

Diese Hürde scheint der Betrüger aber mühelos überwunden zu haben; schon im zweiten der überlieferten Briefe heißt es am 23. Juni 1802:

Geliebter, der du mir alles bist! Ich sehne mich verzweifelt danach, Dich hier während ein oder zwei Stunden allein zu sehen, um bloß von niemandem gestört zu werden. Ich warte mit einer Ungeduld auf diesen Augenblick, die sich mit einer ebenso großen Furcht davor vermengt, welchen Eindruck wir aufeinander machen werden; in alles, was ich von Dir weiß, bin ich verliebt, aber ich versuche nicht, mir deine Gestalt vorzustellen. ${ }^{48}$

Damit sind schon die wesentlichen Motive der nachfolgenden noch über 100 Briefe angesprochen: Die unbedingte Liebe in der Hypostasierung der subjektiven Bedeutung des Geliebten für den Schreiber, die verzweifelte Sehnsucht nach einer unmittelbaren Begegnung und damit nach der Überwindung des rein epistolaren und insofern defizitären Status der Gemeinsamkeit; die Hoffnung auf ungestörte Intimität und die Ängste eben davor. Von Müller ist ein erfahrener Liebesbrief-Verfasser, und er setzt all seine sprachlichen Befähigungen für das entscheidende Ziel ein: die Überwindung der räumlichen Distanz zum Geliebten und damit der epistolaren Beschränkung dieser Liebe - auch hier zeigt sich: der Brief als Liebesbrief will sich selber überwinden. Zugleich ist für eine Interpretation $\mathrm{zu}$ berücksichtigen der oben zitierte Brief an den Bruder hat dies verdeutlicht -, dass Müller seine innersten Gefühle ebenso präzise wie rhetorisch brillant zu gestalten vermag, und zwar mit Blick auf eine mögliche Veröffentlichung dieser zutiefst persönlichen und zudem ,verbotenen“ Briefe. Diese doppelte Codierung - Mittel zur tatsächlichen Vereinigung mit dem Geliebten und zugleich Teil des als Selbstzweck verstandenen Werkes eines Genies zu sein ${ }^{49}$ - ist mithin für die folgende Betrachtung zu berücksichtigen. Anhand welcher Themen realisiert Müller seine Selbstaussprache als Liebender und Geliebter des Grafen Batthyány, den er bald mit dem vertrauten „Louis“ anspricht?

48 Müller 2014, Bd. I, 21-22.

49 Müller macht auch in seinen Briefen an den Geliebten deutlich, worum es ihm mit seiner Arbeit zu tun ist: „Aber einen allgemeinen Plan mußte ich machen, dann immer lebe ich in Gedanken viel beÿ der Nachwelt u. möchte gern Beweise hinterlassen dessen, was in mir war.“ Müller 2014, Bd. I, 100. 


\section{Liebe und Gelehrsamkeit}

Zwei Gegenstands- und Reflexionsbereiche ragen erkennbar in quantitativer und qualitativer Hinsicht aus der Fülle an Themen, mit denen Müller seine Briefe ausgestaltet, heraus: Da ist zum einen die ausführliche Thematisierung der eigenen Empfindungen gegenüber dem schnell als Geliebten identifizierten Louis, d.h. umfangreiche, ausdrucksstarke und stets um Varianz, d.h. die Verhinderung von Langeweile und Überdruss, ${ }^{50}$ bemühte Schilderungen der Gefühle des verliebten Müller; schon der erste Satz der überlieferten Briefe schildert das müllersche Gefühlsleben und dessen Verhältnis zum dieses beschreibenden Brief:

Mein verehrungswürdiger Freund, Du hast mich geradezu von Empfindungen trunken gemacht; meine Seele streitet mit der Zunge, Dir alles auszudrücken, was Du, oh mein unvergleichlicher Louis, mich erleiden lässt. ${ }^{51}$

Aber Müller kann solcherart Gefühlsaufwallung noch viel drastischer in Briefworte fassen; kurz vor einem der stets vereitelten Treffen, auf die er je und je zuschreibt, weil er sie mit seinem Schreiben anstrebt, heißt es zum Ende eines Briefes in nachgerade ekstatischer Manier:

Ich soll zu Bette gehen, mit innigster Rührung, lieber Bruder, lege ich die Feder nieder, Du kannst Dir leicht vorstellen, daß ich einschlafe u. erwache mit meinem Einigen; u. nicht aus Lüsternheit so wie in einem unausdrückbaren Gefühl, was es mir seÿn wird, Dich in meine Arme zu schliessen, Deinen Busen an mein Herz zu drüken, den Geliebten meiner Seele gantz zu fühlen wie nun bloß desselben moralisches (so schönes, edles, hohes!) Bild. Gute Nacht, mein Louis! In der $4^{\text {ten }}$ Nacht nach dieser wie wird mir seÿn! Sagen werde ich Dir nicht so viel, aber empfinden das unempfundene - o wie mich schmiegen an die treüe, mannhafte, Freundesbrust! O Gute Nacht heüte kan ich nicht mehr! Ich bin Dein; gantz; ewig!!!52

Müller schildert und inszeniert, d. h. er gestaltet sich sprachlich hier als ein von seinen Gefühlen und Erwartungen überwältigter, erschöpfter und hingebungsvoller

50 Müller befürchtet stets, den Geliebten zu langweilen, daher macht er diese Angst zum Thema und überpotenziert sie ausgerechnet zu einem ,Verbrechen wider die Natur' (d.h. zu einem an sich naturrechtswidrigen Vergehen, als das vor allem die Homosexualität galt, vgl. Stiening 2020). So heißt es in einem frühen Brief: „Ich werde dir nichts mehr davon [d. i. von einem neuen Publikationsprojekt] erzählen, bevor ich nicht weiß, ob solche Gegenstände irgendein Interesse für dich haben: denn ich fürchte mich unaussprechlich, ein Verbrechen wider die Natur zu begehen. Dieses Verbrechen besteht darin, die Leute zu langweilen, da die Natur uns zum Handeln und Genießen geschaffen hat und nicht, um vor Langeweile umzukommen“. Müller 2014, Bd. I, 22.

51 Müller 2014, Bd. I, 9.

52 Müller 2014, Bd. I, 304. 
Liebender, dem jedes Mittel recht ist, sein einziges Ziel, die mehr als ,moralische‘, d. h. hier anhand des Porträts geistige, nämlich ,physische‘, ${ }^{53}$ d.h. hier keineswegs sexuelle, aber doch körperliche Gemeinsamkeit zu erreichen. Diese körperliche Dimension der ersehnten Vereinigung wird häufig und wie selbstverständlich aufgerufen, wobei von Müller eindeutig sexuelle Anspielungen, Sehnsüchte und Wünsche, die sich wohl auch in Zeichnungen ausdrückten, eigens eingelegten Zettelchen anvertraute ${ }^{54}$ - sicher auch im Hinblick auf die Publikation der eigentlichen Liebesbriefe und deren Produktionsbedingungen.

Deren Zentrum bildet daher auch eher die ,moralische‘, d.h. hier mentale und psychische Dimension der Verbindung, die von Müller durch die unterschiedlichsten Prädikate fasst, welche er für die Ansprache an Louis findet: Er bezeichnet ihn als „Bruder“ ebenso wie als „Freund“ und als „Geliebten“; gleichsam zum ,Gatten“ wird Batthyány darüber hinaus durch die Einbeziehung der Mutter des Grafen, die sich von Hartenberg ebenfalls einfallen lässt ${ }^{55}$ und an die von Müller eine Fülle empfindsamer Briefe verfasst, deren dritter schon eingeleitet wird mit der Formel: „Grosse Mutter, Mutter der brüderlichen Freünde.“56 Diese familiäre Dimension, die Müllers Sehnsüchte nach einer gefestigten, quasi-ehelichen, natürlich aristokratischen Verbindung bedienen, erlangt schnell eine Legitimation der Lebensgemeinschaft durch die ,Mutter‘ und befördert damit die ,Authentizitätsfiktion' des Betruges ganz erheblich.

Müller ist fortan zum anderen darum bemüht, eine Sprache der Liebe zu finden, die nicht allein seine Gefühle, sondern den Gehalt und die Bedeutung der Liebesgemeinschaft herauspräpariert; dazu gehört zunächst die Gebärde der Unterwerfung:

Eines nur, das Louis, mußt du mir versprechen, darauf bestehe ich durchaus, dann das ist die Hauptsache: durchaus in allem Wahrheit, ohne einige Schonung; Du Held der Freündschaft (denn das ist Dein Charakter) weist ja, daß das Gegentheil Hochverrath an ihr wäre. Wir zweÿ können einander so wenig ärgern als betrüben; Ein Händedruck, ein Kuß macht alles gut. Alles mußt du mir sagen was Du an mir u. meinen Sachen anders wünschest, nie verheelen, wenn ich Dich ennüÿire, oder sonst gegen eine zarte Seite Deines Hertzens anstosse. ${ }^{57}$

53 Der müllerschen Terminologie des ,Moralischen` liegt die seit Samuel Pufendorf geläufige Unterscheidung zwischen entia physica und entia moralia zugrunde, wobei die ,moralischen Dinge ‘ alle Formen des Mentalen und Psychischen - keineswegs nur die normativen - implizieren; diese Terminologie differenziert mithin ganz allgemein zwischen Natur und Geist (vgl. auch in ebendieser Bedeutung Müller 2014, Bd. I, 292); vgl. hierzu u. a. Lutterbeck 2009.

54 Müller 2014, Bd. I, 147 u. ö.

55 Vgl. hierzu Weibel 2014, 119-111.

56 Müller 2014, Bd. I, 106.

57 Müller 2014, Bd. I, 156. 
Neben der psychischen Funktion der Prävention von Verlust und der Einhegung der Ängste vor ihm dient die Verpflichtung auf die Wahrheit auch der Unterordnung der beiderseitigen Liebe unter ein höheres Prinzip und damit einer Verstärkung der Verbindlichkeit der ethischen Dimension der Verbindung; nur so kann deren mögliche Brechung mit der strafrechtlich relevanten Bestimmung des „Hochverrats“ belegt werden, der an sich nur gegenüber einer staatlichen Gemeinschaft begangen werden kann, hier aber auf die Liebesgemeinschaft zwischen von Müller und von Batthyány übertragen wird; übrigens sah noch das preußische Allgemeine Landrecht von 1794 für alle Formen des Hochverrats die Todesstrafe vor. ${ }^{58}$ In Müllers Geste der Unterwerfung unter die Vorlieben des Geliebten liegt mithin zugleich die Androhung der gewaltsamen Beherrschung durch Strafe.

Die Unterordnung der Liebesgemeinschaft unter höhere Prinzipien gehört aber überhaupt zum Arsenal ihrer Beschwörung durch Müller: Dabei sind die Kontexte der Überhöhung der Liebe durch Unterordnung unter überindividuelle Instanzen weniger kulturelle oder politische als nahezu ausschließlich religiöse: Schon im soeben zitierten Brief vom 25. Juli 1802 hatte Müller Gott als Lenkungsinstanz der intellektuellen Gemeinschaft mit Louis aufgerufen. Im unmittelbar anschließenden Brief vom 26. Juli wird die Gottesinstanz jedoch sogar als Schöpfer der Liebe zwischen ,Johannes und Louis“ in Anspruch genommen: „Du kostbares Himmelsgeschenk! “59

Mag das noch zur Topik der Liebesbriefrhetorik zu zählen sein, so wird das Bedingungsverhältnis zwischen der Gottesinstanz und dem Geliebten in der Folge gar umgekehrt, im Rahmen einer mehrfach erwähnten Lektüre von Chateaubriands Le Génie du christianisme heißt es mit einiger Emphase:

Wenn Chateaubriand in der Folge nicht besser wird, so werf' ich ihn weg. Meine Demonstration ist viel besser: weil Du so gut bist, so ist eine unendliche Güte, deren Ausfluß Du bist; weil ich den fand dessen ich bedurfte, so ist ein Führer der Schiksale, da der ewig seÿn muß, kan auch sein Werk nicht vergehen; unter allen Veränderungen werden wir fortexistiren $\mathrm{u}$. sein liebes Werk, unsere Freündschaft, vernichtet er nicht. Wie findest diesen Katechismus? ${ }^{60}$

Die Güte des Geliebten und die Sehnsuchtserfüllung des Liebenden gelten in diesem Zusammenhang als Gottesbeweise in gleichsam physikotheologischer Manier; dieser ,Beweis‘ der Existenz Gottes ermöglicht sodann den Grund für die Annahme der Unsterblichkeit der Liebe und der Liebenden selbst, weil der gütige Gott diese Vollkommenheit nicht wieder zerstören kann - ein Immortalitätsbeweis, den vor

58 Vgl. hierzu Bitter 2013, 203-221.

59 Müller 2014, Bd. I, 158.

60 Müller 2014, Bd. I, 279. 
allem Mendelssohn bekannt gemacht hatte, allerdings ohne Referenz auf ein innerweltliches (gar homosexuelles) Liebesverhältnis. ${ }^{61}$ Der Unsterblichkeitsgedanke wird im Übrigen von Müller schon weit vor dieser ,Demonstration“ häufiger aufgerufen, um den überirdischen (keineswegs übersinnlichen) Status dieser Liebe zum Ausdruck zu bringen. ${ }^{62}$ Unverkennbar zählt die Aufrufung des Unsterblichkeitstopos zum Liebesgesäusel, mithin zur Rhetorik einer Sprache der Liebe seit dem Mittelalter; gleichwohl ist die Bindung des Unsterblichkeitsbeweises an eine irdische, gar homosexuelle Liebe und dessen Ableitung aus einem ,amourösen Gottesbeweis' ebenso ungewöhnlich wie durch Müllers Bildung und Gottvertrauen konsequent - hatte doch auch Wieland in der dritten, 1794 publizierten Auflage seines Agathon eine zunächst ganz materialistische Schülerin des Hippias, Danae, einen Unsterblichkeitsglauben annehmen lassen, und zwar durch ihre vollkommen unverfügbare Liebe zum Protagonisten. ${ }^{63}$ Kurz: Einerseits weiß Müller die religiöse Überhöhung seiner und des Geliebten Liebe für eine wirkungsvolle Rhetorik einzusetzen, andererseits dokumentiert diese Nobilitierung das Selbst- und Gemeinschaftsverständnis des Schreibers, der trotz aller theologischer und religionspraktischer Verurteilung der Homosexualität um 1800 seine mannmännliche Liebe im christlichen Glauben aufgehoben sieht. ${ }^{64}$

Diese Nobilitierungsanstrengungen, die Müller eben auch auf sich nimmt, um den noch nie gesehenen Geliebten an sich zu binden und ihn zu einem Treffen zu überreden, begründet sich darüber hinaus durch die spezifische Form der angestrebten Gemeinschaft, die nicht allein durch die für Müller ganz selbstverständliche Homosexualität ausgemacht wird, sondern vor allem dadurch, dass der Briefschreiber eine gelehrte Liebe bzw. eine verliebte Gelehrsamkeit anzustreben hoffen kann, weil von Hartenberg den ungarischen Grafen als Gelehrten, wenigstens aber ausnehmend Gebildeten inszeniert. Dieses Moment der gemeinsamen Gelehrsamkeit steht im Zentrum der müllerschen Vorstellungen von und Hoffnungen auf das Zusammenleben mit Batthyány und wird zunächst und zumeist durch Berichte der eigenen Lektüre befeuert. Neben Horaz, Plutarch und Cicero sind es u. a. Montesquieu, Rousseau und Gibbon oder der schon erwähnte Chateaubriand, deren Lektüre geschildert und deren Ausführungen z.T. ausführlich kommentiert werden. Dabei versteht Müller diese mit vielerlei Zitaten ausgeschmückten Darlegungen erkennbar als Liebeswerben um den gelehrten Freund, weil er einerseits die gemeinsame Lektüre als Zweck, nicht als Mittel der Liebesgemeinschaft versteht; im Rahmen eines Referats aus Cicero und Montaigne heißt es denn auch:

61 Vgl. hierzu u. a. Pollok 2017.

62 Vgl. u. a. Müller 2014, Bd. I, 68, 100, 123.

63 Wieland 1986 ( $\left.{ }^{1} 1794\right), 1,73-176$.

64 Vgl. hierzu u. a. Dabhoiwala 2014, 152-164. 
Wir müssen das alles lesen, langsam, miteinander; das ist unser Katechismus, unser Gesetzbuch. Was sagte ich da? Ich nach meiner Kenntniß des Charakters dieser Männer und der unsrigen behaupte, $u$. vermag zu beweisen, daß unsere Freündschaft die von ihnen geschilderte noch weit übertrift, eine innigere, grössere aber gar nicht denkbar ist. ${ }^{65}$

Einer der wesentlichen und häufig erwähnten Gegenstände der Lektüre sind mithin klassische Freundschaftstheorien, die im Hinblick auf ihre Aussagekraft für das Verhältnis zwischen Müller und Batthyány geprüft und zumeist als unzureichend verworfen werden. Für dieses Superioritätsargument, das erkennbar auch ein Liebeswerben ist, referiert Müller zum einen auf seine - noch näher zu betrachtende - wissenschaftstheoretische Position, nach der die menschliche Erfahrung jeder Theorie überlegen ist, und zum anderen auf den Sachverhalt, dass die klassischen Freundschaftstheorien von Aristoteles bis Montaigne der homosexuellen Komponente entbehren und so defizitär bleiben müssen. Doch noch die mehrfach aufgerufenen Beispiele homosexueller Gelehrtenfreundschaften werden gegen die eigene Liebe abgewogen und häufig für defizitär befunden, so heißt es zu Edward Gibbons Autobiographie: 66

Hast Gibbon's von ihm selbst beschriebenes Leben nie gesehen? Ich vor einigen Monaten mit vielem Vergnügen; er lebte mit einem Freünd, das war mir ein grosser Punct; auch sonst waren Aehnlichkeiten auffallend; doch glaube ich, unter uns gesagt, daß wir als Männer ihn u. seinen d'Iverdon übertreffen. ${ }^{67}$

Müller ist in seinem eigentümlichen Liebeswerben zugleich behutsam und zugreifend: Zwar stellt er sich nicht mit Gibbon als Gelehrtem und europaweit geehrtem Historiker auf eine Stufe, aber in ihrer privaten Liebesbeziehung als „Männer“ sieht er sich und ,seinen' Louis einem Gibbon und ,dessen“ Jacques Georges Deyverdun durchaus überlegen, weil inniger verbunden.

Dabei macht das Eigentümliche des liebenden Selbstverständnisses eben jene Kombination aus Liebe, Homosexualität und Gelehrsamkeit aus, deren spezifische Vermittlung nach Müller ihn und Batthyány zu einem gleichsam genialischen Gelehrtenpaar und zu gelehrten Liebesgenies erhebt. Dafür müssen sich aber alle drei Komponenten gegenseitig ins Verhältnis setzen lassen; so ist für Müller die Liebe zwischen ihm und Louis ein, ja der höchste Gegenstand seiner Studien:

65 Müller 2014, Bd. I, 108-109.

66 Vgl. hierzu Gibbon 1984 (1796).

67 Müller 2014, Bd. I, 169. 
Denn, Louis, ich betrachte unsere Liebe als das allerernsteste, feÿerlichste Geschäft unseres Lebens, das ich daher gantz von allen Seiten studiere. Oder weist du etwas grösseres? Gewiß nicht; corfirmans animis, beÿde Männer, wählen wir u. wissen was wir thun. ${ }^{68}$

Zugleich erhebt Müller die gelehrte Liebe zwischen Louis und ihm zur Bedingung der Möglichkeit tatsächlich wissenschaftlicher Historiographie:

In der That, Gott wollte es. Mein Beruf, von Natur, ist, Geschichtsschreiber zu seÿn. Eben war ich im Begrif, das größte aller historischen Werke zu unternehmen: Da war denn die allererste Erforderniß Wahrheit. Aber die erfordert - Unabhängigkeit. Es dürfte also keine Regierung in der gantzen Welt mein Glük machen; auch nicht eine Nation; auch nicht eine grosse Familie; das alles macht unvermerkt partheÿisch. Da kam der Freünd meines Hertzens, der selbst keiner Familie so recht eigentlich angehörig daß er für sie von mir Parteÿlichkeit fordern möchte. Also schreibt Jean [d.i. Müller selbst] gantz nach seiner Ueberzeügung. [...] Dann, wann künftige Geschlechter sagen, Nur in Müllers Buch ist reine Wahrheit, u. sagen, denn Louis $\mathrm{B}^{\mathrm{ni}}$ sein Freünd hat ihn freÿ gemacht. ${ }^{69}$

Es ist also ausschließlich die Liebe zwischen Müller und Batthyány - nicht etwa dessen Vermögen oder seine aristokratische Herkunft -, die dem Historiker jene Form von ,Objektivität in den historischen Wissenschaften` erlaubt, die dieser häufig interessensgebundenen Forschung abgeht; ausschließlich Louis’ Liebe macht Müller recht eigentlich zum Wissenschaftler im Feld der Historiographie ja zum größten aller Historiker. Damit ist ersichtlich, dass die Liebe zu Batthyány nach Müller sowohl Selbstzweck als auch Gegenstand und Bedingungen der wissenschaftlichen Gelehrsamkeit ist, die beide Gebildeten zugleich in ihrer Liebe verbindet; es ist und muss aber eine attische Liebe sein, weil nur in dieser beide Liebenden nach Müller Gelehrte sein können. ${ }^{70}$

\subsection{Die „Welt“: Reisen, die Französische Revolution und die Techniken des Verbergens}

Müller thematisiert allerdings keineswegs nur seine Gefühle und die erstrebten Formen und Ausprägungen dieser homosexuellen Gelehrtenliebe. Vielmehr beschreibt er auch ausführlich seine Lebensbedingungen, und zwar einerseits, um sich dem Freund vorzustellen, andererseits aber, um sich dem zukünftigen Lesepublikum zu präsentieren. Dabei skizziert er gerne seinen Tagesablauf und die

68 Müller 2014, Bd. I, 108.

69 Müller 2014, Bd. I, 154.

70 Müller neigte - insbesondere im Hinblick auf weibliche Gelehrsamkeit - zur Misogynie; vgl. u. a. Müller 2014, Bd. I, 37-38. 
Räumlichkeit seiner Wohnung, um in diese Beschreibung die zukünftige Stellung und Rolle ,seines Louis' zu imaginieren. ${ }^{71}$ Von Hartenberg alias Batthyány heizt aber vor allem Müllers Sehnsucht nach einem anderen Leben an, indem er Umzüge nach Spanien ${ }^{72}$ oder Reisen nach Rom vorschlägt und damit Müllers Einbildungskraft in Aktivität versetzt; von den Reisemodalitäten und Vorbereitungen durch Reisebeschreibungen ${ }^{73}$ über die Routen und Zwischenaufenthalte ${ }^{74}$ - alles wird ausführlich und oft mehrfach von Müller ausgebreitet; auch die Arten sicherer Finanzierung der Reise in unsicheren Zeiten werden von Müller ausgiebig erörtert:

Mir ist eingefallen, daß wir freÿlich an gute Wechselhäuser zu Genf, Genua (oder Livorno oder Florenz) und Rom offene Creditbriefe nehmen, doch aber nicht unweislich thäten, eine mit Gold gefüllte Chatoulle zu haben, womit wir äusserst knauserig wären, auf den Fall nur, wo der Wechselcurs irgend gesperrt würde, um, wie die Bären, eine Zeitlang von unserm eigenen Spek zu zehren. Aber die Kunst ist, sie im Wagen unbemerkt so einzunageln, daß auch Räuber sie nicht leicht finden könnten. ${ }^{75}$

Solcherart lebensweltliche Sachverhalte werden zumeist durch eindeutige Signale zu bloß äußeren Mitteln der Gemeinsamkeitsrealisation herabgestimmt und bisweilen als lästige, bisweilen, weil als Zeichen der Zuneigung ausgeschmückt, als innige Beschäftigungen bezeichnet. Etwas anders stellt sich diese Darstellung der ,Welt‘ als jener Sphäre, die dem Liebespaar letztlich äußerlich und daher auch verachtenswert ist, bei der Schilderung des Hoflebens oder der Zusammentreffen mit hochrangigen Adeligen dar; ${ }^{76}$ Müller dokumentiert hierbei mit großer Raffinesse, dass er nach wie vor ein durchaus geschätzter Teil dieses Sozialsystems ist, womit er offenkundig auf einen Reputationsgewinn beim ungarischen Aristokraten setzt. Doch auch in diesem Zusammenhang inszeniert Müller rhetorisch brillant den Status jenes Sozialsystems als einer, Welt', die der Liebe zwischen ,Jean und Louis“ äußerlich bleiben muss.

Ein gänzlich anderes Bild bieten Müllers Schilderungen und Bewertungen dieser ,Welt', wenn es um die Ereignisse in Frankreich seit 1789 und deren Auswirkungen auf ganz Europa geht. Müller legt erkennbar großen Wert darauf, sich als entschiedener Revolutionsgegner darzustellen, und wird zu diesem Zweck auch gerne deutlich; gegenüber der angeblichen Mutter, Maria Theresia von Falkenstein, heißt es in einer polemischen Engführung von Revolution und Liebe:

71 Vgl. etwa Müller 2014, Bd. I, 100.

72 Müller 2014, Bd. I, 103-140.

73 Müller 2014, Bd. I, 257-259.

74 Müller 2014, Bd. I, 272.

75 Müller 2014, Bd. I, 274.

76 Vgl. u. a. Müller 2014, Bd. I, 166. 
Sie haben die Welt gesehen und kennen ohne Zweifel auch die Geschichte, Sie wissen, dass eine Freundschaft wie die zwischen Louis und seinem Freund Jean ziemlich außergewöhnlich ist; insbesondere in einem Zeitalter, in dem das Wanken vieler Grundsätze einen feigen Egoismus und das schnöde Interesse mehr als jemals ins Zentrum beinahe aller Systeme gerückt hat, aber alles wird eher untergehen, als das man meine Freundschaft für Louis, der mein alles ist, sich wandeln sieht. ${ }^{77}$

Egoismus und Interesse - Müller beklagt nicht allein die revolutionären Veränderungen der Zeit, er hat auch stets die seit Friedrich Schiller und Friedrich Gentz gängige Verbindung zwischen dem als ,gräuliche Anarchie“78 denunzierten politischen System in Frankreich und ,der Aufklärungsphilosophie‘ zur Hand; dabei werden in der Manier des gentzschen Konservativismus bestimmte Philosopheme (vor allem des Utilitarismus und des Materialismus) mit der Aufklärung schlechthin identifiziert; im Rahmen einer positiven Charakterisierung Montesquieus heißt es dazu:

Der Praesident [d. i. Montesquieu] ging als ein sehr gelehrter Mann den Weg der Erfahrung; die neüeren, nichts weniger als unterrichteten Philosophen giengen den ihrer grundlosen Speculation, woraus die Revolution entstanden ist. Unstreitig hat dieses fürchterliche Experiment, dessen Unkosten die Menschheit bezahlt, viel alte Sätze auf Probe gestellt [.....$^{79}$

Solcherart gentzsche Revolutionskritik in Reinkultur ${ }^{80}$ wird aber zugleich auch verwendet, um das erhoffte Liebesverhältnis in die Kultivierung einer Gegenkonzeption einzubetten:

Bruder, Mit Deinem Verstand siehst Du so gut als ich die Lage der Welt unserer Zeiten. Meinerseits, verwünsche ich alle Revolutionen von Hertzensgrund; ich bin für mich gantz dem Genuß des Guten u. Schönen, das ich vereinigt finde in Dir, u. für andere wünsche ich die Evolution, die natürlich sich entwikelnden Fortschritte, alles wilde Wesen u. die zerstörende Metapolitik ist mir ein Gräul. ${ }^{81}$

Doch nicht nur die geschichtsphilosophischen Entwicklungsgesetze von ,Revolution' und ,Evolution' werden von dem liebenden Historiker streng entgegengesetzt; er kann auch deutlicher politisch werden und dabei ein klares Bekenntnis zur autoritären, alle Gewaltenteilung negierenden, patriarchalischen Monarchie abliefern:

77 Müller 2014, Bd. I, 98.

78 Müller 2014, Bd. I, 294.

79 Müller 2014, Bd. I, 170.

80 Vgl. hierzu Burke u. Gentz 1991 (1792), 467: „Der Philosoph formt Systeme, der Pöbel schmiedet Mordgewehre daraus. Es kann kein schrecklicher Schwert in den Händen eines ungebildeten Menschen geben als ein allgemeines Prinzip.“

81 Müller 2014, Bd. I, 31. 
Das ist gewiß, daß, wenn unsere Sachen (die der Monarchie) etwas venünftiger gehen, der Kaiser u. seine Kinder ihr Lebenlang sicher u. glüklich regieren u. Oesterreich immer eine gewaltige Vormauer gegen den allgemeinen Ruin bleiben kann $u$. wird. Alles beruhet auf der Leitung. ${ }^{82}$

Es kann überhaupt kein Zweifel daran bestehen, dass Müller - wie sein jahrelanger Freund Friedrich Gentz - ein in der Wolle gefärbter Konservativer war, der weniger als ein Opfer der „Dialektik der Aufklärung“83 denn vielmehr als ein gegenaufklärerischer, anti-revolutionärer Täter zu interpretieren ist, dem alle Rechts- und Verfassungsstaatlichkeit, alle Egalität und politische Freiheitskonzeptionen ein „Gräuel“ waren. ${ }^{84}$ Es ist an den Briefen an Batthyány nicht zu erkennen, dass diese strikt rechtsstaats- und demokratiefeindliche Position, die als anti-bürgerliche Haltung inszeniert wird, aus den Aversionen eines großen Teils der Aufklärungsphilosophie gegen die attische Liebe erwachsen sei, die zu Exzessen der negativen Bewertungen und Strafvorstellungen in Theorie und Praxis führten, ${ }^{85}$ vielmehr scheint von Müller aus tatsächlich und ausschließlich staats- und herrschaftspolitischen Gründen ein überzeugter Verteidiger des monarchischen Prinzips gewesen zu sein, das ihn ab 1807 auch zu Napoleon überlaufen ließ. Das Zerwürfnis mit Gentz, der ihn wegen seiner öffentlichen Napoleon-Apologie mit homophoben Beschimpfungen überzog, ${ }^{86} \mathrm{kann}$ an dieser rein politischen Bewertung von Müllers Konservativismus nichts ändern: Er war und blieb bis ans Ende seiner Tage ein Vertreter des monarchischen Prinzips. ${ }^{87}$

Es wird jedoch der weiteren Forschung überlassen bleiben müssen, ob die Option für die aristokratische Ständegesellschaft und deren politische Garantie in der Monarchie nicht auch durch deren relative Toleranz gegenüber homosexuellen Lebensformen veranlasst wurde. Sicher ist, dass die wenigen gelassenen Urteile der Aufklärungstheorie zur ,attischen Liebe‘ aus der Mailänder Aufklärung stammten, deren aristokratische Sozialstruktur bekannt ist; ${ }^{88}$ oder von dem als Epikureer denunzierten Wieland, der eine bedeutende Ausnahme bildete. ${ }^{89}$ Das Gros der von Müller mit dem dritten Stand verbundenen Aufklärungsphilosophie war ebenso wie die Theologie und die religiöse Praxis der Zeit bis zum Exzess homophob.

82 Müller 2014, Bd. I, 165.

83 So aber Weibel 2014, 21.

84 Dass sich Müller in diesem Zusammenhang in ein breites Theoriespektrum eingliedert, lässt sich nachlesen bei Garber 1992.

85 Vgl. Derks 1990, 140-173 und Stiening 2020.

86 Vgl. hierzu ausführlich Derks 1990, 324-328.

$87 \mathrm{Zu}$ dessen Konturen vgl. Wehler ${ }^{3} 1996,370-376$.

88 Vgl. hierzu Stiening 2020, 109-110.

89 Vgl. hierzu Derks 1990, 232-246. 
Doch auch die Wiener Aristokratenkultur hatte ihre klaren Grenzen im Hinblick auf eine Toleranz homosexueller Lebensformen; ein öffentliches gemeinsames Leben war letztlich, wenn auch von Müller in halböffentlicher Weise angestrebt, ohne Heimlichkeiten nicht zu haben. Deshalb hat die eigentümliche Verbindung einer prätendierten Offenheit einer homosexuellen Lebensgemeinschaft mit spezifischen Techniken der Geheimhaltung einen durchaus gewichtigen Raum in Müllers Briefen:

Wir sind uns, wie ich glaube, einig; wir werden unsere Freundschaft nicht verbergen, wir werden sie verehrungswürdig und ruhmreich gestalten; und werden darauf, Arm in Arm, unsern Weg gehen auf dieser verschlungenen und finstern Straße, die sich den Bewohnern der gegenwärtigen Welt aufthut! Du weißt, was wir Fritz sein werden; auch was George; ohne dieselbe Vertraulichkeit mit unseren anderen Treuen zu pflegen, sofern Du sie ihnen nicht bereits erwiesen hast (dann trete ich dem Pakt gerne bei), muss man sie mit dem Zutrauen behandeln, das Leute verdienen, die unsere Geheimnisse kennen, ohne es sich anmerken zu lassen (und man muss das tun, um der Gefahr zu entgehen, mit ihnen, mit ihnen in dauernder, lächerlicher und völlig unnötiger Verlegenheit zu sein); mit den anderen werden wir so sein - wie wir sein müssen..$^{90}$

Müller sucht hier den Geliebten auf bestimmte Verhaltensweisen im Hinblick auf eine abgestufte soziale Offenheit der homosexuellen Lebensgemeinschaft einzuschwören; denn Müller ist - und er ist es gerne - Teil der Wiener aristokratischen Gesellschaft, ${ }^{91}$ und er will diese Stellung offenkundig nicht wirklich einbüßen. Daher muss er die ebenso diffizilen wie komplexen Techniken der Gradualisierung des Verbergens - und Enthüllens dem zukünftigen ,Gatten' früh nahebringen; auch um jene Skandale zu vermeiden, die seine frühen Unvorsichtigkeiten provozierten. ${ }^{92}$ Es sind diese Passagen, die ein Proprium des ,Briefwechsels‘ ausmachen, weil einerseits das Verbotene dieser Liebe nicht allein ständische, sondern auch im Verständnis der Zeit - natürliche und religiöse Ordnung verletzte; andererseits bot die relative Toleranz gegenüber homosexuellen Lebensformen innerhalb des großstädtisch-aristokratischen Sozialsystems offenkundig die Möglichkeit, der Hoffnung Ausdruck zu verleihen, die „Freundschaft nicht verbergen“ zu müssen. Das wird sich kulturgeschichtlich wieder ändern: Die Romantik, der Müller ästhetisch und politisch huldigt, wird dieser Toleranz massiv Einhalt gebieten - weit bis in die zweite Hälfte des zwanzigsten Jahrhunderts.

\footnotetext{
90 Müller 2014, Bd. I, 60.

91 Vgl. Müller 2014, Bd. I, 166.

92 Weibel 2014, 44-46.
} 
Um 1800 aber konnte Müller davon ausgehen, dass es neben den realen Schwulenszenen in London, Paris oder eben Wien ${ }^{93}$ auch ideelle Kontexte gab, in denen und durch die eine Tolerierung der griechische Liebe aktiv betrieben und propagiert wurde; Müller berichtet darüber am 24. September 1802:

Man hat mir heüte von Weimar geschrieben, jene von mir gedrukten Briefe [d. i. der BonstettenBriefwechsel] seÿn das Handbuch für alle Jünglinge und Männer von Gefühl und Genie, u. es seÿ nur Ein Jubel darüber. Es freüt mich recht sehr; sowol weil sie würklichen Eifer für wahre Gelehrsamkeit erweken können, als selbst wegen des Mißverstandes: 9 unter 10 werden in dieser Freündschaft finden, was ich frë̈lich gern hineingelegt hätte; das belustigt mich u. ich widerlege es nicht; dann in Wahrheit bin ich für solcher Freündschaften, sie machen männlich u. geben einen höhern Sinn. ${ }^{94}$

Bei aller indignierten Kritik daran, dass man in Weimar die Gelehrsamkeit seiner Briefe an Bonstetten nicht zur Kenntnis nimmt, sondern ausschließlich deren Feier der mannmännlichen Liebe - Müller kann erfreut und gelassen auf den Vorstoß Goethes, den dieser u. a. mit seinem in Arbeit befindlichen Buch über Winckelmann unternahm, ${ }^{95}$ reagieren und diese Kampagne als Zeichen dafür verstehen, die anvisierte Lebensgemeinschaft mit Louis offener realisieren zu können.

\subsection{Epistolarität}

Wie in vielen anderen Briefwechseln insbesondere des achtzehnten Jahrhunderts wird auch in Müllers Liebesbriefen auf das Medium der Kommunikation selbst, den Brief, referiert. Dabei wird diese epistolare Selbstreflexion von Müller als Instrument der imaginierten Selbstüberwindung nach erfolgter realer Vereinigung in der Liebesgemeinschaft inszeniert:

Eines Tages werden wir meine Briefe erneut lesen; wir werden den Gang, den unser Herz genommen hat, noch einmal abschreiten; aber ich sehe voraus, das es damit gehen wird wie mir mit den Deinen; ich kenne sie beinahe auswendig. ${ }^{96}$

Kaum nachdrücklicher und doch zugleich behutsamer hätte ein auf seine Briefe reduzierter Liebender seine Sehnsucht nach der Überwindung dieser Epistolarität seiner Liebe ausdrücken können - in der Imagination der gemeinsamen Lektüre ebenjener Briefe, an denen er just schreibt, nach deren Überwindung in der

93 Vgl. hierzu Weibel 2014, 109-110.

94 Müller 2014, Bd. I, 291.

95 Vgl. hierzu u. a. Tobin 2017, v. a. 67-68.

96 Müller 2014, Bd. I, 147. 
erinnernden Rückkehr zu ihnen - das ist Sehnsucht im Modus imaginierter Souveränität. Müller kann dieses Thema aber auch noch geschickter einsetzen, um Louis von seiner Liebe zu überzeugen und damit ein Zusammentreffen zu erwirken: So werden der Tatsache, dass diese Liebe ausschließlich durch Briefe zustande kam und sich noch immer nur in ihnen realisiert, dergestalt positive Seiten abgewonnen, dass die Stärke seiner Leidenschaften eine echte Kenntnis des Geliebten im Rahmen eines zunächst unmittelbaren Zusammentreffens verhindert hätte:

Daß ich dir so viel schreibe, Bruder, ist, weil ich nicht anders kann. Aber meine Leidenschaft entschuldigt sich mit Vernunft: Ich weiß kein wichtigeres Geschäft für mich, als Dich von mir gantz zu unterrichten; denn auf all mein Thun $u$. Lassen wird nichts mächtiger würken als unsere Liebe. Glüklich daß sie so angefangen; im Taumel der Gegenwart hätten wir uns lange nicht von allen Seiten so genau kennen gelernt. ${ }^{97}$

Müllers Nobilitierung der reinen Brieflichkeit seiner Liebe zu Batthyány ist hier nahe an der Erkenntnis der reflektierenden Eigenleistungen des Briefes, die eine unmittelbare Interaktion - zumal unter Liebenden - nicht erlaubt. Zugleich bleiben diese Nobilitierungen verzweifelt bzw. werden zunehmend verzweifelter; im September 1802 heißt es denn auch:

Wie froh bin ich, daß unsere Freündschaft so wunderbar anfieng; man hätte die Sÿmpathie sonst der sinnlichen Zuneigung zuschreiben können; so, kein Zweifel, wir, was wesentlich wir sind, wir lieben uns, auf so lang also als wir bleiben, 25 Jahre dann, u. si quis piorum manibus locus, si, ut sapientibus placet, non cum corpore existinguuntur magiae animae, noch in der künftigen Welt. ${ }^{98}$

Hier wird die Tatsache, dass ihre Liebe ausschließlich über Briefe inauguriert wurde und so nur sublimierte Sinnlichkeit erlaubte, zum Argument für die Unsterblichkeit ihrer Seelen genommen; enger kann Defizitkompensation und metaphysische Nobilitierung - und damit Liebe und Gelehrsamkeit - kaum ausgeführt werden.

Müller bedient sich der mehrfach zitierten Lizenzen des Briefes zur ausführlichen Selbstdarstellung auch weidlich; sicher nicht allein zur näheren Charakterisierung gegenüber Batthyány, sondern auch mit Blick auf das künftige Lesepublikum zählt zu diesen Selbstdarstellungen auch die präzise Konturierung seiner wissenschaftstheoretischen Position, die allerdings unmittelbar in ein Verhältnis zur Liebesbeziehung gesetzt wird; so heißt es am 23. Juli 1802:

Meines Lebens Trachten war was die Alten Weisheit nennen; Kenntniß der Natur des Menschen u. seiner Verhältnisse. Darum war ich in Schriftsteller, die der Natur am nächsten

97 Müller 2014, Bd. I, 162.

98 Müller 2014, Bd. I, 298. 
waren, immer verliebt. Das nützliche suchte ich; nicht Witz, sondern gesunden Verstand, nicht Schein sondern Seÿn. Darum bist auch, Unvergleichlicher! Du mir so unendlich lieber mit Deinem Kopf u. Hertzen als wenn du der berühmteste Gelehrte von Eüropa wärest. Ich habe nichts weniger als überspannte Ideen (denn unsere Freündschaft, für welche allein ich schwärme, ist im Grunde doch vernünftig $u$. natürlich), bin ein Feind aller Schulgrübeleÿen und metaphÿsischen Formeln. ${ }^{99}$

Diese bemerkenswerte Passage erstreckt sich noch erheblich weiter. Müller entdeckt sich dem Geliebten (und dem Publikum) hier als Anthropologe und Popularphilosoph, dem die Wissenschaft vom Menschen kein Selbstzweck, sondern nützliches Mittel für die Menschheit und deren Fortschritt ist und sein soll. Und es ist ausgerechnet dieses auf „Weisheit“, also auf anwendbare Wissenschaften abzielende Wissenschaftsverständnis, das eine unmittelbare Verbindung zu seiner Liebe ermöglicht, weil sie auf Praxis ausgerichtet ist. Popularphilosophische Anthropologie wird so zur Bedingung der Möglichkeit des Nachweises der Vernunft der Homosexualität. Das ist - vor dem Hintergrund der rassistischen, misogynen und homophoben Tendenz der Anthropologie der Spätaufklärung ${ }^{100}$ - ebenso brillant wie gewagt.

\subsection{Zur Rolle Hartenbergs - zur Dialektik von Nähe und Distanz}

Die vorstehende Skizze einer Interpretation der Liebesbriefe Johannes von Müllers an Graf Louis Batthyány Szent-Iványi kann nicht abgeschlossen werden ohne einen Blick auf die Rolle des Betrügers, der die Briefe eigentlich schreibt, sie überbringt und zusammen mit Müller häufig gar liest und ausführlich bespricht. Dabei erweist sich von Hartenberg nicht nur als brillanter Brieffälscher, sondern auch als überzeugender Schauspieler, der die ihm von Batthyány (also ihm selbst) und Müller zugewiesene Rolle des ,Sohnes‘ nachgerade liebevoll ausfüllt:

Es war ein herrlicher Abend; 3 Stunden blieben wir beÿ einander, unser Fr. u. ich; er war unvergleichlich, wahr, hertzlich; von allem denkbaren wurde gesprochen, in dem Ton welchen Du Dir denken kannst. Nur Du fehltest. Wir träumten von dem Glük, einst alle 3 eine Reise zu machen, von all den Scenen im Wagen, von allen Erfindungen lustiger Schelmereÿ. Dann war er mit unter recht vernünftig, zärtlich; für unsere Mutter, daß sie sich nicht überarbeite, daß wir unrecht haben, so zu pressiren; Ihr gütiger Eifer könnte ihr schädlich werden. Dann wurde die Welt seiner Liebschaften durchwandert. Am genauesten aber mein Louis beschrieben; denn was hatte ich nicht alles zu fragen! $u$. feürig wurde das glükliche Portrait geküßt. ${ }^{101}$

99 Müller 2014, Bd. I, 149-150.

100 Vgl. hierzu u. a. Stiening 2012.

101 Müller 2014, Bd. I, 152-153. 
Müller ist außer sich und offenkundig ohne jeden Schutz dem mit allen Wassern gewaschenen Betrüger ausgeliefert. Von Hartenberg kennt aber sein Opfer offenkundig zu gut, um nicht alle Register ziehen zu können - und er scheint ohne jeden Skrupel zu agieren. Gerade weil er aber das gefährliche Schauspiel der innigen, auch erotischen Bekanntschaft zu seiner eigenen Kunstfigur überzeugend aufzuführen versteht, verstärkt er den Authentizitätscharakter der von ihm überbrachten, vor allem aber geschriebenen Briefe.

Müller aber, der sich in niemand anderen als den Schreiber jener Briefe verliebte, ist dem Objekt seiner Wünsche und Begierden während der zehn Monate seiner Illusion und des hartenbergschen Betruges nie näher als in den oben geschilderten Situationen; er ist seinem Geliebten - dem tatsächlichen Schreiber der Briefe nämlich - damit näher, als ihm bewusst ist und sein kann - und ihm doch zugleich so fern, wie nur möglich: nämlich letztlich unüberwindlich. Denn seine Liebe richtet sich nicht auf den tatsächlichen Schreiber, sondern auf die von Hartenberg erfundene Kunstfigur des ungarischen Grafen. Größte Nähe und größte Distanz fallen hier folglich zusammen - im Medium des Briefes als Fälschung. Die Voraussetzung dieser abenteuerlichen Dialektik bilden sowohl der technisch in mehrfacher Hinsicht brillante Betrug von Hartenbergs als auch die jahrzehntelange unerfüllte Sehnsucht Müllers nach einer gelehrten Homosexuellenehe sowie seine hemmungslose Egomanie, die ihn noch in den Hochzeiten seiner Leidenschaft an die Publikation von deren epistolaren Erzeugnissen denken ließ.

\section{Literatur}

Altman, Janet G. (1982). Epistolarity. Approaches to a Form. Columbus.

Beetz, Manfred u. Johannes von Lüpke (Hg.) (2016). Hamanns Briefwechsel. Acta des Zehnten Internationalen Hamann-Kolloquiums an der Martin-Luther-Universität Halle-Wittenberg 2010. Göttingen.

Benz, Maximilian (2018). Fragmente einer Sprache der Liebe um 1200. Zürich.

Bitter, Albrecht von (2013). Das Strafrecht des Preußischen Allgemeinen Landrechts von 1794 vor dem ideengeschichtlichen Hintergrund seiner Zeit. Baden-Baden.

Bredthauer, Stefanie (2020). „Fingierte Briefe und Brieffälschungen. Sprachliche Verstellungen in inkriminierten Briefen“, in: Handbuch Brief. Von der Frühen Neuzeit bis zur Gegenwart. Hg. v. Marie Isabel Matthews-Schlinzig, Jörg Schuster, Gesa Steinbrink u. Jochen Strobel. Bd. 1: Interdisziplinarität - Systematische Perspektiven - Briefgenres. Berlin u. Boston: 291-299.

Burke, Edmund u. Friedrich Gentz (1991 [1792]). Über die Französische Revolution. Betrachtungen und Abhandlungen. Hg. u. mit einem Anhang versehen v. Hermann Klenner. Berlin.

Dabhoiwala, Faramerz (2014). Lust und Freiheit. Die Geschichte der ersten sexuellen Revolution. Stuttgart.

Derks, Manfred (1990). Die Schande der heiligen Päderastie. Homosexualität und Öffentlichkeit in der deutschen Literatur 1750-1850. Berlin. 
Domeier, Norman u. Christian Mühling (Hg.) (2020). Homosexualität am Hofe. Praktiken und Diskurse vom Mittelalter bis heute. Frankfurt a. M.

Garber, Jörn (1992). „Drei Theoriemodelle frühkonservativer Revolutionskritik“, in: Ders.: Spätabsolutismus und bürgerliche Gesellschaft. Frankfurt a. M.: 331-363.

Gibbon, Edward (1984 [1796]). Memoirs of my Life. London.

Goethe, Johann Wolfgang ( $\left.{ }^{3} 1988\right)$. Goethes Briefe und Briefe an Goethe. Hamburger Ausgabe in 6 Bänden. Hg. v. Karl Robert Mandelkow. München.

Grafigny, Françoise de (2020 [1747]). Briefe einer Peruanerin. Aus dem Französischen übersetzt u. mit einem Nachwort v. Renate Kroll. Zürich.

Hamann, Johann Georg (2018 [1785-1787]). Fliegender Brief. Mit einer Einführung, Kommentar u. Dokumenten zur Entstehungsgeschichte hg. v. Janina Reibold. 2 Bde. Hamburg.

Heijden, Adrianus Franciscus Theodorus van der (1995). Der Anwalt der Hähne. Frankfurt a. M. Henking, Karl (1909-1928). Johannes von Müller. 2 Bde. Stuttgart u. Berlin.

Henrich, Dieter (1993). Selbstverhältnisse. Gedanken und Auslegungen zu den Grundlagen der klassischen deutschen Philosophie. Stuttgart.

Jamme, Christoph u. Otto Pöggeler (Hg.) (1986). Johannes von Müller - Geschichtsschreiber der Goethezeit. Schaffhausen.

Keller, Gottfried (1993)[1874]. Die mißbrauchten Liebesbriefe, in: Ders.: Die Leute von Seldwyla. Erzählungen. Hg. v. Bernd Neumann. Stuttgart: 357-430.

König, Caroline u. Rosina Ziegenhain (2020). „Neuere Kommunikationsmedien im Vergleich zum Brief - E-Mail, SMS, WhatsApp und Facebook“, in: Handbuch Brief. Von der Frühen Neuzeit bis zur Gegenwart. Hg. v. Marie Isabel Matthews-Schlinzig, Jörg Schuster, Gesa Steinbrink u. Jochen Strobel. Bd. 2: Historische Perspektiven - Netzwerke - Zeitgenossenschaften. Berlin u. Boston: 1508-1517.

Koschorke, Albrecht (1999). Körperströme und Schriftverkehr. Mediologie des 18. Jahrhunderts. München.

Lenz, Jakob Michael Reinhold (1992 [1797]). Der Waldbruder, ein Pendant zu Werthers Leiden, in: Ders.: Werke und Briefe in drei Bänden. Hg. v. Sigrid Damm. Bd. 2. Frankfurt a. M.: 380-412.

Ludolph, Matthias (1997). Epistolographie und Selbstdarstellung. Untersuchungen zu den ,Paradebriefen" Plinius des Jüngeren. Tübingen.

Lutterbeck, Klaus-Gert (2009). „Pufendorfs Unterscheidung von physischem und moralischem Sein und seine politische Theorie“, in: Naturrecht und Staatstheorie bei Samuel Pufendorf. Hg. v. Dieter Hüning. Baden-Baden: 19-35.

Miller, Norbert (1968). Der empfindsame Erzähler. Untersuchungen an Romananfängen des 18. Jahrhunderts. München.

Moravetz, Monika (1990). Formen der Rezeptionslenkung im Briefroman des 18. Jahrhunderts. Richardsons „Clarissa“, Rousseaus „Nouvelle Héloïse“ und de Laclos' „Liaisons Dangereuses“. Tübingen.

Müller, Johannes von (1835). Briefe an Carl Viktor von Bonstetten. Geschrieben vom Jahre 1773 bis 1809. Hg. v. Friederika Brun, geb. Münter. 3 Bde. Stuttgart u. Tübingen.

Müller, Johannes von (2014). „Einen Spiegel hast gefunden, der in allem Dich reflektirt“. Briefe an Graf Louis Batthyány Szent-Iványi 1802-1803. Hg. v. André Weibel. 2 Bde. Göttingen.

Pape, Matthias (1989). Johannes von Müller. Sein geistiges und politisches Umfeld in Wien und Berlin. Stuttgart.

Picard, Hans Rudolf (1971). Die Illusion der Wirklichkeit im Briefroman des achtzehnten Jahrhunderts. Heidelberg. 
Pollok, Anne (2017). „How to dry your tears? Abbt, Mendelssohn, and Herder on the Immortality of the Soul“, in: Aufklärung 29: 73-88.

Richardson, Samuel (1967 [1748]). Clarissa or, the History of a young Lady. Ed. and introduced by John Butt. 4 vols. London u. New York.

Rousseau, Jean-Jacques (1964 [1761]). Julie, ou: La Nouvelle Héloïse. Texte établi par Henri Coulet et annoté par Bernard Guyon, in: Ders.: Guvres complètes. Èdition publiée sous la direction de Bernard Gagnebin et Marcel Raymond. Vol. II. Paris.

Schib, Karl (1967). Johannes von Müller 1752-1809. Thayngen-Schaffhausen.

Schöne, Albrecht (1967). „Über Goethes Brief an Behrisch vom 10. November 1767“, in: Festschrift für Richard Alewyn. Hg. v. Herbert Singer u. Benno von Wiese. Köln u. Graz: 193-229.

Schöne, Albrecht (2015). Der Briefschreiber Goethe. München.

Stauf, Renate, Annette Simonis u. Jörg Paulus (Hg.) (2008). Der Liebesbrief. Schriftkultur und Medienwechsel vom 18. Jahrhundert bis zur Gegenwart. Berlin u. New York.

Stiening, Gideon (2001). „Body-lotion. Körpergeschichte und Literaturwissenschaft“, in: Scientia Poetica, 5: 183-215.

Stiening, Gideon (2005). „Briefroman und Empfindsamkeit“, in: Das Projekt der Empfindsamkeit und der Ursprung der Moderne. Richard Alewyns Sentimentalismusforschungen und ihr epochaler Kontext. Hg. v. Klaus Garber u. Ute Széll. München: 161-190.

Stiening, Gideon (2012). ,,Es gibt gar keine verschiedenen Arten von Menschen.' Systematizität und historische Semantik am Beispiel der Kant-Forster-Kontroverse zum Begriff der Menschenrasse“, in: Klopffechtereien - Missverständnisse - Widersprüche? Methodische und methodologische Perspektiven auf die Kant-Forster-Kontroverse. Hg. v. Rainer Godel u. Gideon Stiening. München: 19-53.

Stiening, Gideon (2020). „,Chi teme il dolore ubbidisce alle leggi.‘ Suizid und attische Liebe in den Strafrechtstheorien Christian Wolffs, Cesare Beccarias und Johann Adam Bergks“, in: Deutsch-italienischer Kulturtransfer im 18. Jahrhundert: Konstellationen, Medien, Kontexte. Hg. v. Chiara Conterno u. Astrid Dröse. Bologna: 81-110.

Stiening, Gideon (im Druck). „Epistolarität als Reflexions- und Darstellungsform. Hamanns Fliegender Brief als religiöse Bekenntnisschrift“, in: „sind noch in der Mache“. Zur Bedeutung der Rhetorik in Hamanns Schriften. Acta des zwölften Internationalen Hamann-Kolloquiums in Heidelberg 2019. Hg. v. Eric Achermann u. Janina Reibold. Göttingen.

Süßmann, Johannes (2004). „Die Darstellungsprinzipien in Johannes von Müllers erstem Geschichtswerk“, in: Geschichtsschreibung zu Beginn des 19. Jahrhunderts im Umkreis Johannes von Müllers und des Groupe de Coppet / L'historiographie à l'aube du XIXe siècle autour de Jean de Müller et du Groupe de Coppet. Hg. v. Doris u. Peter Walser-Wilhelm. Paris: 79-109.

Tobin, Robert Deam (2017). „Winckelmann - Homosexualität, schwule Kultur, Queer Theory“, in: Winckelmann-Handbuch. Leben - Werk - Wirkung. Hg. v. Martin Disselkamp u. Fausto Testa. Stuttgart: 65-72.

Vellusig, Robert (2000). Schriftliche Gespräche. Briefkultur im 18. Jahrhundert. Wien, Köln, Weimar.

Voss, E. Theodor (1993). „Gellerten sagen Sie davon nichts“, in: Das achtzehnte Jahrhundert 17,1: 50-54.

Wehler, Hans-Ulrich ( $\left.{ }^{3} 1996\right)$. Deutsche Gesellschaftsgeschichte. Bd. 2: Von der Reformära bis zur industriellen und politischen Doppelrevolution 1815-1845/49. München.

Weibel, André (2014). „Schwindel des Glücks. Johannes von Müller, Friedrich von Hartenberg und die Wiener ,Batthyány-Affäre““, in: Johannes von Müller: „Einen Spiegel hast gefunden, 
der in allem Dich reflektirt“. Briefe an Graf Louis Batthyány Szent-Iványi 1802-1803. Hg. v. André Weibel. Bd. 2. Göttingen: 5-172.

Wieland, Christoph Martin (1986 [31794]). Geschichte des Agathon. Hg. v. Klaus Manger. Frankfurt a. M. 
